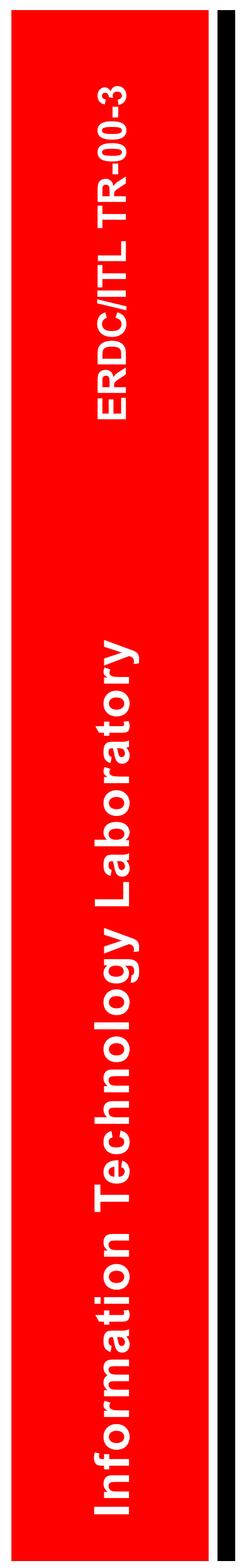

Investigation of Risk Assessment Methodology for Dam Gates and Associated Operating Equipment

Chandra S. Putcha and Robert C. Patev

November 2000 
The contents of this report are not to be used for advertising, publication, or promotional purposes. Citation of trade names does not constitute an official endorsement or approval of the use of such commercial products.

The findings of this report are not to be construed as an official Department of the Army position, unless so designated by other authorized documents. 


\section{Investigation of Risk Assessment Methodology for Dam Gates and Associated Operating Equipment}

By Chandra S. Putcha

California State University

Fullerton, CA 92834

Robert C. Patev

Information Technology Laboratory

U.S. Army Engineer Research and Development Center

3909 Halls Ferry Road

Vicksburg, MS 39180-6199

Final report

Approved for public release; distribution is unlimited 


\section{Contents}

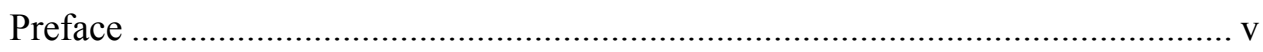

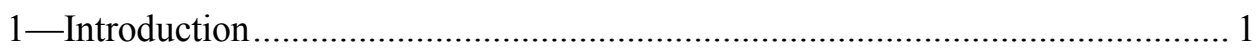

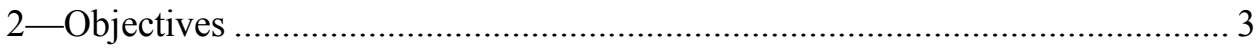

3-FMEACA or FMECA (Failure Modes and Effects and Criticality

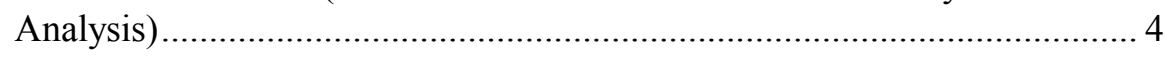

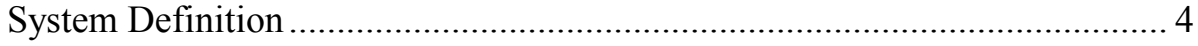

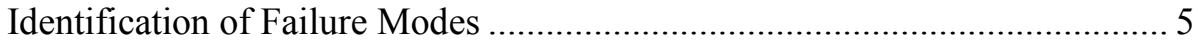

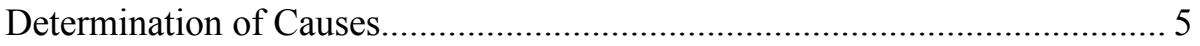

Assessment of Effect ……………………………………………….... 5

Classification of Severity........................................................................ 5

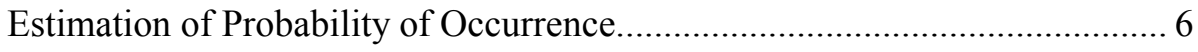

Computation of Criticality Index …………………………………………........ 6

Determination of Corrective Action ............................................................ 7

4-Interdependencies of Components/Events................................................ 8

Event and Fault Tree Analysis................................................................. 8

Other Analysis Methods ……………………………………………….. 9

5 Detailed Literature Review....................................................................... 10

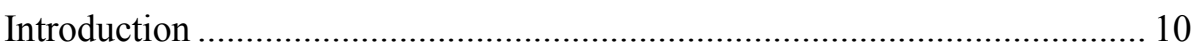

Summary of Available Methods for Risk Assessment of Dam Gates............ 10

6-Limited Literature Review of Risk Assessment Methods for Warning

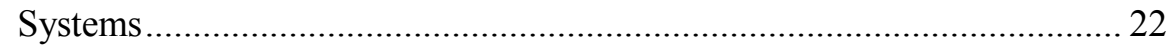

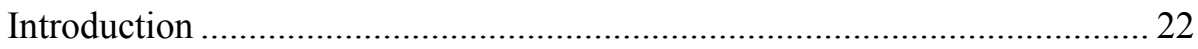

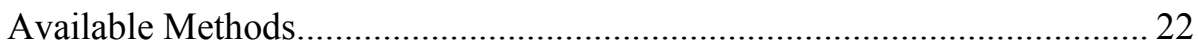

7-Recommended Methods For Risk Assessment For Dam Gates ...................... 26

A. Probability Based Evaluation of the Safety and Risk of Existing Dams (Kreuzer and Bury 1984)....................................................... 26

B. Wind Induced Overtopping Risk of Dams (Cheng et al. 1986) ............... 29

C. Probabilistic Risk Analysis of Large Dams: Its Value and Limits (Lafitte 1993) Based on Method by Gruetter and Schnitter (1982) 
D. Predicting Loss of Life in Cases of Dam Failure and Flash Flood (Dekay and McClelland 1993)........................................................... 34

E. Classes Of Risk For Dams (Lafitte 1996) ............................................. 35

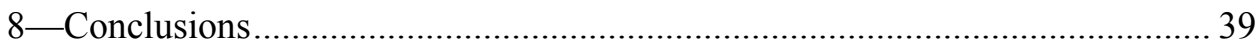

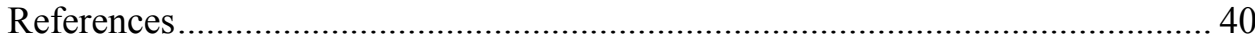

SF 298 


\section{Preface}

This report describes the results of an investigation of the various risk assessment methods to be used for dam gates and associated operating equipment. The funding for this research project was provided by Headquarters, U.S. Army Corps of Engineers, under the Risk Analysis for Dam Safety R\&D Program. The research was conducted and the report was compiled by Dr. Chandra Putcha, California State University - Fullerton, and Mr. Robert C. Patev, formerly of the Scientific and Engineering Applications Center (SEAC), Computer-Aided Engineering Division (CAED), Information Technology Laboratory (ITL), Engineer Research and Development Center (ERDC). The authors gratefully acknowledge Ms. Diana Lopez for typing the original manuscript and the InterLibrary loan staff at California State University - Fullerton for their support and assistance.

The research effort and report were coordinated by Mr. Patev. Mr. H. Wayne Jones was Chief, CAED, and Mr. Timothy D. Ables was Acting Director, ITL.

At the time of publication of this report, Dr. James R. Houston was Director of ERDC. COL James S. Weller, EN, was Commander. 


\section{Introduction}

Dams are essential for any society. The main purposes of dam construction are for water supply, hydropower, flood control, irrigation, and navigation. The possible events that could initiate a dam failure are listed (McCann et al. 1985) as:

a. Static reservoir loads

b. Floods

c. Structural deterioration

d. Upstream dams

e. Foundation weakness

f. Seepage

g. Earthquakes

h. Mechanical failure

i. $\quad$ Flooding

(1) Life loss

(2) Injury, property damage

j. Operator error

Out of these only a few initiating failures are dominant contributors to risk. These dominant modes of failures vary depending on type of dam, i.e., earth dam, concrete dam, etc. The causes of dam failure can be grouped into external and internal events.

The factors contributing to external events are upstream dam failure, hydrologic events (including flood frequency, volume, peak, initial water stage in the reservoir prior to flood, etc.), earthquake (including seismic stability of dam, liquefaction, etc.), and landslide into the reservoir to name a few (McCann et al. 1985; Cheng, Yeng, andTang 1982).

The factors contributing to internal events are structural and construction factors (including inadequate structural design, inadequate quality control, inferior material used, etc.), deterioration, piping (in the embankment, foundation, etc., as 
well as around outlet works, etc.), hydraulic factors (including spillway capacity, flood routing, sluice, erosion and scour protection, and faulty gates or valves), mechanical failure of valves, motors, etc. on demand, and foundation failure to name a few.

As stated before, dominant modes of failure vary depending on type of dam constructed. Hence, some statistics in this regard are relevant. It has been reported by the Department of the Army (1982) that $90 \%$ of dams constructed are earth dams followed by gravity dams which constitute about $5 \%$. It has also been reported by Bivins (1983) and Department of the Army (1982) that for about 80\% of dams the primary deficiency of the dam is due to inadequate spillway capacity, followed by seepage (8\%). In another report (Cheng, Yeng, and Tang 1982) dealing with mainly earth dams, it was reported that overtopping and piping constitute major causes of dam failure $(23-36 \%, 30 \%-44 \%$, respectively). The important point to be noted is that the consequences of dam failure can be catastrophic as it could involve loss of life. Therein lies the importance of warning systems in the event of a possible flood inundation due to a dam breach.

A research project to identify risk assessment methodologies pertaining to dam gates and associated operating equipment was initiated by the U.S. Army Engineer Research and Development Center (ERDC), Vicksburg, MS. The project was divided into two phases:

Phase I: Review of Risk Assessment Methodologies for Dam Gates Existing in the Literature

Phase II: Implementation of a Proposed Method to a Dam Gate and Associated Operating Equipment

This report deals with Phase I and incorporates a complete review of the literature to understand the behavior of dam structural components including their electrical/mechanical components and the associated system and intercomponent dependencies. 


\section{Objectives}

The objectives of the study reported herein are as follows:

a. Perform a detailed literature review of all the existing methods for risk assessment of dams. Investigate the applicability of these methods dealing with failure modes for dam gates to structural components, as well as mechanical and electrical operating systems. Investigate possible interdependencies between components.

b. Perform brief review of the literature on early warning systems with respect to dam structures.

c. Recommend a method/methods suitable for risk assessment methodology that can be used for flood control and reservoir dam gates. 


\section{FMEACA or FMECA (Failure Modes and Effects and Criticality Analysis)}

Since one of the objectives of the proposed research as stated above is investigation of applicability of the risk assessment methods dealing with failure modes for dam gates, it is important to look into the concepts of this analysis as it exists in the literature. Failure Modes and Effects Analysis (FMEA) is a basic tool to evaluate design at the initial stage from the reliability aspect (Dhillon and Singh 1981). These criteria help to identify need for and the effects of design change. FMEA becomes failure modes, effects, and criticality analysis (FMEACA or FMECA) if criticalities are assigned to failure mode effects. There are various references in the literature dealing with FMECA (Military Standard MIL-STD1629A 1980; Henley and Kumamoto 1981; Nelson 1982; Shooman 1990; Leemis 1995; Ebeling 1997). FMECA is often performed as a bottom-up analysis, though it can be applied at any level if sufficient data exist (Ebeling 1997). FMECA is an inductive process that systematically details on a component-by-component basis, i.e., individual failures are generalized into possible failure modes (Henley and Kumamoto 1981; Ebeling 1997). FMECA essentially consists of the following eight steps (Ebeling 1997):

1. System Definition

2. Identification of Failure Modes

3. Determination of Cause

4. Assessment of Effect

5. Classification of Severity

6. Estimation of Probability of Occurrence

7. Computation of Criticality Index

8. Determination of Corrective Action

\section{System Definition}

In this step, system components that will be subject to failure are identified. The physical description of the system is depicted by an indenture diagram showing subassemblies, components, and parts along with their hierarchical relationships. It is important to clearly define acceptable performance 
specifications under expected operating and environmental conditions in order to define failures. A Reliability Block Diagram (RBD) may be used based on the functional analysis or hardware configuration or a combination of both. The functional approach requires a top-down analysis of the system whereas the hardware approach is usually a bottom-up analysis.

\section{Identification of Failure Modes}

Failure modes are the observable manners in which a component fails. Failure modes are identified in this step either by component (hardware approach) or function using a RBD. Examples include shorts, opens, ruptures, power losses, etc.

\section{Determination of Causes}

For each failure mode a determination is made as to the probable cause or causes. Typical causes are given below:

a. Friction: Common cause of failures in belts, gears, and machinery in general

b. Contamination: Dirt can cause electrical failure

c. Corrosion: Chemical change that weakens material

A failure mode may have more than one cause. For example, for an item such as a motor case, the failure mode of rupture can be caused by poor workmanship, defective materials, damage during transportation, damage during handling, and over-pressurization.

\section{Assessment of Effect}

In this step, impact of each failure on the operation of the system is assessed. The effects may range from complete system failure to partial degradation to no effect. Sometimes, in redundant systems, the system reliability will be reduced by failure of a redundant unit without affecting the system's performance immediately. In the example of motor case above, the possible effect could be destruction of missile.

\section{Classification of Severity}

A severity classification is assigned to each failure mode. Four possible classifications of severities are used:

Category 1: Catastrophic Failure resulting in loss of life or major damage. 
Category 2: Critical

Complete loss of system such as potential mission failure.

Category 3: Marginal System is degraded with partial loss in performance.

Category 4: Negligible No effect on acceptable system performance

For the motor case problem discussed above, the severity level is critical.

\section{Estimation of Probability of Occurrence}

The probability of occurrence is based on the expected number of occurrences of each failure mode over a specified interval. This interval may be a mission time, a scheduled maintenance interval, or the system design life. When sufficient data does not exist for quantifying the probability of occurrence, Military Standard MIL-STD-1629A (1980) is used for qualitative grouping of failure mode frequencies over the operating time interval:

Level A: Frequent - High probability of failure $(\mathrm{p} \geq 0.20)$

Level B: Probable - Moderate probability of failure $(0.10 \leq p \leq 0.20)$

Level C: Occasional - Marginal probability of failure $(0.01 \leq p \leq 0.10)$

Level D: Remote - Unlikely probability of failure $(0.001 \leq p \leq 0.01)$

Level E: Extremely Unlikely - Rare event $(\mathrm{p}<0.001)$

For the motor case problem discussed earlier the probability of occurrence is 0.0006 , hence this failure mode is classified as extremely unlikely.

\section{Computation of Criticality Index}

This is a quantitative measure of the criticality of the failure mode that combines the probability of the failure mode's occurrence with its severity ranking. The equation used is

$$
C_{k}=\alpha_{k p} \beta_{k} \lambda_{p} t
$$

where

$$
\begin{aligned}
C_{k}= & \text { criticality index for failure mode } k \\
\alpha_{k p}= & \text { fraction of the component } p \text { 's failures having failure mode } k \text { (i.e. the } \\
& \text { conditional probability of failure mode } k \text { given component } p \text { has failed) }
\end{aligned}
$$


$\beta_{k}=$ conditional probability that failure mode $k$ will result in the identified failure effect

$\lambda_{p}=$ failure rate of component $p$

$t=$ duration of time used in the analysis

$\beta_{k}$ is a subjective estimate, which is quantified as per guidelines (Military Standards MIL-STD-1629A 1980).

\begin{tabular}{ll} 
Failure Effect & \multicolumn{1}{c}{$\beta$} \\
\cline { 2 - 2 } Certain & $\beta=1.00$ \\
Probable & $0.10<\beta<1.00$ \\
Possible & $0<\beta<0.10$ \\
No Effect & $\beta=0$
\end{tabular}

\section{Determination of Corrective Action}

Corrective action is dependent on the problem. It is important that those failure modes having a high criticality index and severity classification should receive most attention. For the motor case problem, one of the corrective actions should be to maintain a close control of manufacturing processes to ensure that workmanship meets prescribed standards. In other words, rigid quality control of basic materials should be maintained. 


\section{Interdependencies of Components/Events}

Since one of the objectives of the research is to examine the possible interdependencies of components, this aspect is discussed herein as it exists in the literature. Event trees, fault trees, and failure modes effects analysis (FMEA) are approaches for considering the arrangements of components in a system (Barlow and Proschan 1981).

\section{Event and Fault Tree Analysis}

A fault tree analysis is a graphical design technique used to analyze complex systems (Dhillon and Singh 1981; Ebeling 1997; Ayyub 1997). The concept of independence/dependence of basic events is discussed with respect to fault trees (Henley and Kumamoto 1981). Dependent events may appear in a fault tree in the following cases:

\section{Standby redundancies}

In this case, failure of an operating component results in a standby component being put into operation. This means that failure of one component affects the failure characteristics of the other component, and component failures are not statistically independent.

\section{Common causes}

The causes creating component failures come from one or more of the following four sources: (1) Aging; (2) Plant Personnel; (3) System Environment; (4) System Components (or Subsystems). So, if a common cause such as fire results in simultaneous failure of components, component failures are dependent. 


\section{Components supporting loads}

A failure of one component increases the load supported by other components in a system where a set of components supports loads such as stresses or currents. In such a case, remaining components are more likely to fail, and the components are statistically dependent.

\section{Mutually exclusive primary events}

This event can occur when the fault tree involves two basic events which are mutually exclusive such as "switch fails to close" and "switch fails to open."

\section{Other Analysis Methods}

$\mathrm{Li}$ and $\mathrm{Li}$ (1989) presented a model for the reliability and performance analysis of systems where components can degrade in a statistically dependent manner. System reliability and performance measures are computed by considering the most probable states. There are other papers in the literature dealing with dependent components (Draper, Evans, and Guttman 1989; Iyer 1992; Schötl 1996).

The concept of associated components was introduced by Barlow and Proschan (1965), wherein it is assumed that if an associated component $\mathrm{C}$ fails, then the other components are assumed to be stressed more intensively.

The unavailability $Q_{s}(t)$ is derived using the inclusion-exclusion principle and is expressed as (Henley and Kumamoto 1981):

$$
\begin{gathered}
Q_{s}(t)=P_{r}\left(\bigcup_{i=1}^{N_{c}} d_{i}\right)=\sum_{i=1}^{N_{c}} P_{r}\left(d_{i}\right)-\sum_{i=2}^{N_{c}} \sum_{j=1}^{i-1} P_{r}\left(d_{i} \bigcap d_{j}\right)+ \\
\ldots . .+(-1)^{N_{c}-1} P_{r}\left(d_{1} \bigcap d_{2} \bigcap \ldots . d_{N_{c}}\right)
\end{gathered}
$$

where

$$
\begin{aligned}
& N_{c}=\text { total number of minimal cuts } \\
& d_{i}=\text { all basic events occurring in the } \mathrm{i}^{\text {th }} \text { minimal cut set at time } \mathrm{t} .
\end{aligned}
$$

The quantification of systems which include dependent events is done using the inclusion-exclusion principle coupled with Markov models. Derman and Ross (1995) discussed the procedure for calculation of multinomial probabilities that maximize the probability of a $k$-of- $n$ system. A simulation method is used that employs a variance reduction technique to estimate the reliability of a system of $n$ components. 


\section{Detailed Literature Review of Risk Assessment Methods for Dam Gates}

\section{Introduction}

An extensive review of the literature was conducted using the library facilities at California State University, Fullerton. Over 50 references are discussed below that can assist in focusing on risk assessment methods for dam gates. These are introduced to the reader in chronological order as discussed in the following section.

\section{Summary of Available Methods for Risk Assessment of Dam Gates}

This summary details methods identified as viable methods for use in risk assessment of dam gates and associated operating equipment. The order of the review is relatively chronological in order to document the development of various authors and the continuation of their work in the field.

\section{Yen, Cheng, and Tang (1980)}

Yen, Cheng, and Tang (1980) applied the concepts of reliability to hydraulic design of culverts. First-order second-moment method is used to determine the reliability or probability of failure. The basic equation used is

$$
P_{f}=\Phi\left[\frac{\ln \left(\mu_{L} / \mu_{R}\right)}{\left(\Omega_{L}^{2}+\Omega_{R}^{2}\right)^{1 / 2}}\right]
$$

where $\mu$ and $\Omega$ are the mean and coefficient of variation, respectively, of a variable. $\Phi($ ) denotes the cumulative standard normal distribution function. $L$ represents the load, and $R$ represents the resistance. 


\section{Bivins (1981)}

Bivins (1981) applied the concepts of risk analysis to dam safety. Two approaches are discussed: Ranking Score (RS) and Screening Process (SP). In the RS method, the dams are ranked based on assigning a numerical score for overtopping failure and structural failure. The relative risk is supposed to be the sum of these two scores. The SP method is mainly based on collecting information on the dam downstream inundation area routing of the floodwave due to dam failure, estimation of life/property loss and, finally, the evaluation of annual probability of failure of the dam and the corresponding expected yearly loss.

\section{Cheng, Yen, and Tang (1982)}

Cheng, Yen, and Tang (1982) discussed various methods for calculation of risk. The main methods discussed are method of return period, method of direct integration, Monte Carlo simulation method, Mean-Value First-Order SecondMoment (MFOSM) method, and, finally, Advanced First-Order, Second-Moment (AFOSM) method. The basic equation used for the method of return period is as follows:

$$
P(Y>Q)=1-\left(1-\frac{1}{T_{r}}\right)^{n}
$$

where, $P()$ represents the risk for an n-year period under consideration. $Y$ and $Q$ represent the actual and design value of the physical variable under consideration and $T_{r}$ denotes the return period. Equation 4 could be used if occurrences of the random variable $Y$ are independent between years and the hydrologic system is invariant.

\section{Vanmarcke and Bohnenblust (1982)}

Vanmarcke and Bohnenblust (1982) discussed specific procedures of riskbased decision analysis as applied to practice of dam engineering. Three different criteria were used dealing with social losses, economic losses and comparison of various contributions to aggregate risk. This report focuses more on decision theory than on the risk assessment methods of dam gates.

\section{Bohnenblust and Vanmarcke (1982)}

Bohnenblust and Vanmarcke (1982) used the concept of decision analysis for prioritizing dams for remedial measures. Like the previous report developed by the same authors, this report doesn't focus on the risk assessment method of dam gates. 


\section{Langseth and Perkins (1983)}

Langseth and Perkins (1983) developed a model to be used for studying influence of dam failure probabilities on spillway analysis. The results show that the traditional thought which assumes that a larger spillway produces a safer dam is not necessarily true. This doesn't directly deal with the objectives of the proposed research as no risk assessment methodology is proposed.

\section{U.S. Department of the Interior Bureau of Reclamation (1983)}

The U.S. Department of the Interior Bureau of Reclamation (1983) provided a comprehensive guide to a program of dam safety examination and evaluation. Various modes and causes of failure dealing with foundation deterioration, defective spillways, concrete deterioration, etc. were discussed. This kind of information could be useful in a fault-tree analysis.

\section{Lee and Mays (1983)}

Lee and Mays (1983) discussed a dynamic risk model to reflect the overall risk of a hydraulic structure incorporating hydrologic and hydraulic uncertainties. Even though expressions for risk values are generated, they don't directly apply to dam gates, but to the overall structure.

\section{Bivins (1983)}

Bivins (1983) discussed the status of dams in the United States in terms of hazard and corresponding economic losses. The paper gives statistical information regarding primary deficiencies of unsafe dams and various owner groups, such as federal and local governments.

\section{Committee on the Safety of Existing Dams (1983)}

The Committee on the Safety of Existing Dams (1983) discussed in detail the concept of risk-based decision analysis. The work is similar to that discussed by Bivins (1983) and Hagen (1982) dealing with relative risk index in terms of overtopping and structural failure scores. No new methodology as relates to objectives of the present research is discussed.

\section{Von Thun (1984)}

Von Thun (1984) discussed the problem of reduction of risk to society due to dam failure of existing dams. Risk-based decision analysis was used to calculate the partial risk cost and total risk cost. Total risk cost was defined as the sum of risk cost for all load levels of all load types and each relevant failure mode. 


\section{Vanmarcke (1984)}

Vanmarcke (1984) developed a procedure for quantifying the benefits of hazard mitigation programs, with specific reference to dams. The paper deals more with risk management rather than with quantification of risk at dam projects.

\section{Kreuzer and Bury (1984)}

Kreuzer and Bury (1984) developed a procedure for the evaluation of dam safety and risk. This is done by identifying primary failure causes and hazardous conditions, selecting load scenarios, and performing cause-failure analysis for each scenario, resulting in a failure probability value. This information is then used to perform failure-consequence evaluation and, finally, estimation of total risk. The basic equation used is:

$$
P_{f}=P(L \geq R)=\int_{R=0}^{L} \int_{L=0}^{\infty} f_{G}(L) f_{N}(R) d R d L
$$

In Equation 5, $L$ represents a critical load and $R$ represents the dam resistance with failure occurring when $L \geq R$. $L$ and $R$ both are treated as random variables.

\section{Lytle (1984)}

Lytle (1984) discussed the evaluation methods dealing with various instruments and installation procedures pertinent to dams. The paper mainly deals with feasibility of automated data and safety acquisition, data reduction, etc. but with no risk-assessment methodologies.

\section{Priscu and Stematiu (1984)}

Priscu and Stematiu (1984) discussed the procedure to quantify failure probability of dams and formulation of design criteria to ensure safety-risk balance. Failure probability expressions were derived using a convolution integral.

\section{Serafim (1984)}

Serafim (1984) proposed a model for judging reliability of concrete dams based on the determination of the total probability of failure. This in turn is determined from the probability of the effects of various loads which have to be lower than the resistance of concrete in all possible scenarios. The paper is casespecific and deals with exceptional loads like maximum flood-water level, silt pressure, etc. 


\section{Widman (1984)}

Widman (1984) suggested that in the design stage, extreme influences should be considered by checking the project during construction and also by assuring proper monitoring equipment. The paper focuses more on dam and reservoir monitoring and maintenance, etc.

\section{Duscha (1984)}

Duscha (1984) recommended adoption of formalized periodic inspection procedures utilizing present technology, development of inundation maps and emergency action plans and development of programs to increase public awareness of the consequences of unsafe dams. No risk assessment methods are discussed in this paper.

\section{Silveira (1984)}

Silveira (1984) discussed the deterioration and failure causes of dams in relation to the age of dam when the failure occurred. The basic equation used is

$$
\left(P_{F}\right)_{g}=\frac{\left(N_{F}\right)_{g}}{\left(N_{E}\right)_{g}}
$$

where

$\left(P_{F}\right)_{g}=$ probability of failure of a given group of dams

$\left(N_{F}\right)_{g}=$ number of dams failing in that group

$\left(N_{E}\right)_{g}=$ number of dams existing in that group

\section{Boccotti and Rosso (1984)}

Boccotti and Rosso (1984) developed a general risk equation given below:

$$
P_{X, L}=\left(1 / T_{X}\right) \int_{o}^{L} \int_{w}^{\alpha} f(\tau) d \tau
$$

where

$$
\begin{aligned}
T_{X}= & \text { return period of the design flood } \\
L= & \text { design life } \\
P_{X, L}= & \text { probability that at least one flood greater than } \mathrm{X} \text { occurs within the next } \mathrm{L} \\
& \text { years }
\end{aligned}
$$




$$
\begin{gathered}
f(\tau)=\text { interarrival time probability density function of destructive floods } \\
w=\text { time interval between the present instant and the next occurrence }
\end{gathered}
$$

\section{Fanelli, Giuseppetti, Bonaldi, Marazio, and Riccioni (1984)}

Fanelli, Giuseppetti, Bonaldi, Marazio, and Riccioni (1984) discussed the concept of time-extended service life simulations and using these to perform statistical analysis. No formal procedure for calculation of probability of failure was presented.

\section{Croucamp and Carmichael (1984)}

Croucamp and Carmichael (1984) gave an account of dams affected by severe floods. The paper deals mainly with specific flood and flood damage of dam and corresponding stability issues.

\section{Bury and Kreuzer (1985)}

Bury and Kreuzer (1985) calculated the probabilities of failure of a particular gravity dam for cause-to-failure event chains of two typical scenarios. The method is similar to the one proposed by the same authors (Kreuzer and Bury 1984).

\section{McCann, Franzini, Kavazanjian, and Shah (1985)}

McCann, Franzini, Kavazanjian, and Shah (1985) in a two-volume report discussed preliminary safety evaluation of existing dams. The probability of failure of a dam is calculated using mean failure rate per year, $\lambda_{T}$, with an exponential distribution. The report also deals with benefit-cost evaluation as well as hydrologic and seismic risk analysis. Volume II of this report is a user's manual detailing the steps to perform a preliminary safety evaluation of existing dams. This is not directly applicable to the present research work dealing with risk assessment of dam gates and associated equipment.

\section{Bury and Kreuzer (1986)}

Bury and Kreuzer (1986) carried out risk assessment by expanding the chain events (Bury and Kreuzer 1985) to include failure-conditioning and consequencemitigating actions. The method is similar to the one proposed by the same authors (Kreuzer and Bury 1984). 


\section{U.S. Department of the Interior Bureau of Reclamation (1986)}

The U.S. Department of the Interior Bureau of Reclamation (1986) provided guidelines to decision analysis in terms of assessing threat to life for dam safety studies. Detailed evaluation procedures were discussed. These deal with selecting flood events, estimating the Population At Risk (PAR) and Loss of Life (warning), evacuation, etc.

\section{Yen, Cheng, and Melching (1986)}

Yen, Cheng, and Melching (1986) discussed the methods of First-Order Second-Moment (FOSM) and Advanced FOSM. The usefulness of a fault-tree to analyze a complex system for reliability is also discussed in this paper. These general concepts are applicable for risk assessment of dams.

\section{Cheng, Yen, and Tang (1986a)}

Cheng, Yen, and Tang (1986a) developed a procedure for evaluation of the overtopping risk due to wind. The performance function is defined as

$$
\begin{aligned}
Z & =\left(H_{C}-H_{O}\right) \\
& -\left[\frac{V_{W}^{2} F}{1400 D}+0.034 a V_{W}^{1.06} F_{e}^{0.47} \exp \left(-0.028 b V_{W}^{0.18} / F_{e}^{0.09}\right)\right]
\end{aligned}
$$

where

$H_{C}=$ elevation of the crest of the dam

$H_{O}=$ undisturbed reservoir water level

$V_{W}=$ wind velocity in miles/hour

$F=$ fetch or length of water surface in miles over which wind blows

$D=$ average depth of reservoir

$F_{e}=$ effective fetch

$a, b=$ coefficients of embankment slopes

Advanced First-Order Second Moment (AFOSM) method is used to calculate the overtopping probability, $\mathrm{b}_{f}$ expressed as

$$
\mathrm{p}_{f}=1-\Phi(\beta)
$$


where $\Phi$ represents cumulative standard normal distribution function. $\beta$ is the reliability index expressed as

$$
\beta=E(z) / \sigma_{z}
$$

where $E(z)$ and $\sigma_{z}$ denote the expected value and standard deviation of $Z$, given in Equation 6. Finally the authors express risk of overtopping due to wind as

$$
P_{W}(T)=1-\exp \left(-v_{w} T \mathrm{p}_{f}\right)
$$

where $v_{w}$ represents the mean occurrence of wind (causing overtopping) which is treated as an extreme event. $P_{W}(T)$ represents the probability of overtopping due to wind. $T$ is the period under consideration.

\section{Cheng, Yen, and Tang (1986b)}

Cheng, Yen, and Tang (1986b) discussed the importance of the coefficient of variation in the risk evaluation procedures by comparing three different probability distributions. Their paper mainly deals with the significance of coefficient of variation, and the information could be useful in general risk evaluation.

\section{Resendiz-Carrillo and Lave (1987)}

Resendiz-Carrillo and Lave (1987) discussed the concept of dam design with the objective of maximizing net social benefits from the dam considering the cost of construction, and the benefits of flood control, recreation, water supply, power generation, and other effects such as those on environment. The paper dealt with the specific aspect of the balancing of risks and benefits that was beyond the main scope of the present research work.

\section{Mays (1987)}

Mays (1987) reviewed the work done in the risk and reliability evaluation of hydraulic structures. Static and dynamic or time-dependent reliability models were discussed. This paper doesn't specifically deal with dam gates and associated operating equipment.

\section{Parrett (1987)}

Parrett (1987) presented Bureau of Reclamation's philosophy in using riskbased analysis methods to select appropriate action in relation to dam safety. The paper mainly dealt with decision questions for safety of dam construction but with no specific methodology. 


\section{Melching, Wenzel, and Yen (1987)}

Melching, Wenzel, and Yen (1987) discussed application of Advanced First Order Second Moment (AFOSM) method to analyze uncertainties in a rainfallrunoff flood frequency model for an analytical derivation of the expected flood exceedance probability considering parameter uncertainty.

\section{Haimes, Petrakian, Karlsson, and Mitsiopulos (1988)}

Haimes, Petrakian, Karlsson, and Mitsiopulos (1988) applied the concepts of multiobjective risk partitioning to dam safety risk analysis. The Partitioned Multiobjective Risk Method (PMRM) mainly attempts to avoid the problems associated with the concept of traditional expected value by collapsing the risk curve into a set of points that represent the conditional expected values for different damage domains. The method is too mathematical and will be difficult to implement.

\section{Vick and Bromwell (1989)}

Vick and Bromwell (1989) applied the concepts of probabilistic risk analysis to the design of a dike in karst terrain. The paper mainly dealt with dike failure.

\section{Petrakian, Haimes, Stakhiv, and Moser (1989)}

Petrakian, Haimes, Stakhiv, and Moser (1989) applied the PMRM for an idealized dam safety case study. The method is too mathematical for implementation.

\section{Stedinger, Heath, and Nagarwalla (1989)}

Stedinger, Heath, and Nagarwalla (1989) applied the concept of event tree analysis for dam safety. An event tree is used to describe the many random factors contributing to major inflow floods, reservoir operation, and possible downstream damages. This in turn allows evaluation of the probability of dam failure and the associated distribution of damages and loss of life. Monte Carlo simulation is used in conjunction with event tree analysis to calculate the actual probability of failure.

\section{Karlsson and Haimes (1989)}

Karlsson and Haimes (1989) applied the PMRM to a dam-safety problem. Again the method is too mathematical for implementation. 


\section{Bureau of Reclamation Safety of Dams Program (1989)}

Bureau of Reclamation Safety of Dams Program (1989) deals with determination of dam failure, flood inundation studies, and assessment of threat to life for dam safety studies. No risk assessment methodology was presented in this report.

\section{Apostolakis (1989)}

Apostolakis (1989) discussed several issues that arise when judgment and data are used in PSA (Probabilistic Safety Assessment). The pooling of the estimates was done using geometric averaging techniques using the following relation:

$$
\lambda_{\max }=\left[\prod_{i=1}^{n} \lambda_{\max , i}\right]^{1 / n}
$$

where, $\lambda_{\text {max }, i}$ is the maximum value that the $i^{\text {th }}$ expert supplied an estimate for each failure rate (the low, recommended, high, and maximum values). $n$ is the number of experts (about 200).

\section{Bowles (1990)}

Bowles (1990) summarized procedures for risk assessment for evaluation of dam safety. The perspectives of owner/operator, the engineer, the risk analyst, and the insurance company as they pertain to dam safety are discussed in the paper by the author.

\section{Systems Safety and Reliability Office (1992)}

Systems Safety and Reliability Office (1992) developed guidelines for performing Failure Modes Effects Analysis (FMEA) dealing with software logic designs. The general concepts of FMEA discussed therein are applicable to risk assessment of dam gates also.

\section{Dekay and McClelland (1993)}

Dekay and McClelland (1993) derived an expression for Loss of Life (LOL) from severe flooding, in terms of Warning Time (WT), the size of the Population At Risk (PAR), and the forcefulness of the flood waters (FORCE) from historical records of dam failures and flash flood cases via logistic regression. The suggested equation is given as 


$$
L O L=\frac{P A R}{1+13.277\left(P A R^{0.440}\right) \exp (0.759(W T)-3.790(F O R C E)+2.223(W T)(F O R C E))}
$$

\section{Lafitte (1993), based on Gruetter and Schnitter (1982)}

Lafitte (1993) developed a relation for Risk R, expressed as:

$$
R=P D^{\alpha}
$$

where

$P=$ probability of the occurrence of the undesirable event

$D=$ probable extent of the damage caused risk

$\alpha=$ risk consequence factor

$\alpha$ is taken as 1 in Equation 14 if the consequences of the occurrence of the undesirable are not serious, otherwise $\alpha$ is taken as greater than 1 .

\section{Lafitte (1996)}

Lafitte (1996) applied the Risk Classification Method developed by ICOLD (1982) to dam safety problems. Three principal criteria were used: (1) General Conditions of the Site (CGS), (2) condition of the structure (CO), and (3) SocioEconomic Conditions Downstream of the dam (CSE). Each of these principal criteria are then subdivided into 'partial' criteria which are assigned numerical values on a scale of 1 to 6 . 1 is the most favorable and 6 is the least favorable. Using these, partial factors are calculated for each of the three principal criteria for each dam. Finally, a Global Factor (FG) is calculated using the weighted average of the three partial factors.

\section{Alla (1996)}

Alla (1996) discussed the role of fusegates in relation to dam safety, stability, operational reliability, and their functioning in extreme conditions. The paper essentially deals with stability against overturning and sliding which is not within the scope of the present research work.

\section{Thompson, Stedinger, and Heath (1997)}

Thompson, Stedinger, and Heath (1997) discussed the efficiency of different evaluation methods: event trees, simple Monte Carlo sampling, Latin Hypercube 
sampling, Importance sampling and an Analytical/Stratified Monte Carlo (AISMC) method to dam safety.

\section{Department of the Army (1997)}

Department of the Army (1997) Engineer Technical Letter 1110-2-549 discussed methods for assessing the reliability of navigational lock and dam mechanical equipment and for establishing an engineering basis for major rehabilitation investment decisions. Expressions are derived for system risk analysis using block diagrams. Lock and dam mission reliability was also discussed. The general concepts discussed could be useful for present research dealing with dam gates risk assessment.

\section{Putcha and Patev (1997)}

Putcha and Patev (1997) applied the concepts of dynamic or time-dependent reliability analysis to navigation structures in which both capacity and demand are treated as time-dependent random variables. The results mainly dealt with the vertical beam of a miter gate.

\section{U.S. Department of the Interior Technical Service Center (1999a)}

U.S. Department of the Interior Technical Service Center (1999a) gave a detailed account of critical areas of mechanical equipment and mechanical equipment failures for various dams. The report covered the period from 1986-99. This information could be useful for preparing fault trees.

\section{U.S. Department of the Interior Technical Service Center (1999b)}

U.S. Department of the Interior Technical Service Center (1999b) prepared a report dealing with a detailed inventory of mechanical equipment at the spillway and outlet work areas of Bureau of Reclamation facilities. This information dealing with various modes of failures could prove to be useful in the Failure Modes and Effects Analysis (FMEA) and the subsequent probability of failure calculations.

\section{Podgorski, Putcha, and Ryan (2000)}

Podgorski, Putcha, and Ryan (2000) performed a detailed Failure Modes Effects Analysis (FMEA) for the orbiter Forward Reaction Control System (FRCS) Interconnect (IC) System (FICS). These concepts could be used for risk assessment of dam gates. 


\section{$6 \quad$ Limited Literature Review of Risk Assessment Methods for Early Warning Systems}

\section{Introduction}

A limited review of the literature on early warning systems with respect to dam gates was also conducted using the library facilities at California State University, Fullerton, CA. These references are discussed below.

\section{Available Methods}

\section{Pate-Cornell (1984)}

Pate-Cornell (1984) applied the concepts of benefit-cost (B-C) to dams with and without monitoring systems. The basic equation used is

$$
\left(\frac{\mathrm{B}}{\mathrm{C}}\right)_{\mathrm{RISK}_{-} \text {ADJUSTED }}=\left(\frac{\mathrm{B}}{\mathrm{C}}\right)_{\text {ORIGINAL }} *(1-\alpha)
$$

where $\alpha$ is the risk-benefit factor. The final derived expression for $(B / C)$ riskadjusted is given below:

$$
\left(\frac{B}{C}\right)_{\text {RISK_ADJUSTED }}=\frac{B-\bar{C}_{F}}{C}
$$

where 


$$
\begin{aligned}
& \bar{C}_{F}=P_{F 1} \sum_{t=1}^{t=5}\left\{\sum_{i=1}^{2} \frac{P R_{i}(t) D R_{i}+L H_{i}(t) C R_{i}}{(1+R)^{t}}+E(t)+L B(t)\right\} \\
& \quad+P_{F 2} \sum_{t=6}^{t=\mathrm{T}}\left\{\sum_{i=1}^{2} \frac{P R_{i}(t) D R_{i}+L H_{i}(t) C R_{i}}{(1+R)^{t}}+E(t)+L B(t)\right\} \\
& P R_{i}(t)=P R_{i}(0)(1+G)^{t} \\
& H_{i}(t)=H_{i}(0)\left(1+G^{1}\right)^{t} \\
& \alpha=\frac{\bar{C}_{F}}{B}
\end{aligned}
$$

$P_{F 1}=$ annual failure probability for the first five years

$P_{F 2}=$ annual failure probability for the remaining lifetime of the dam

$T=$ lifetime of the dam

$G=$ annual growth rate of economic and financial properties in the area

$G^{1}=$ annual growth rate of the population

$L=$ "value of life" (or maximum accepted cost of human safety)

$\alpha=$ risk-benefit factor

$i=$ index of the two flooding zones; $i=1$ for the path of the wave, $i=2$ for the rest of the flooding zone

$D R_{i}=$ damage ratio in each zone

$C R_{i}=$ casualty ratio in each zone

$B=$ total discounted benefit of the project

$C=$ total discounted cost of the project

$H_{i}(t)=$ number of inhabitants in each zone at year $\mathrm{t}$

$P R_{i}(t)=$ property at risk in each zone at year $\mathrm{t}$

$$
R=\text { social rate of discount }
$$


$E(t)=$ the loss of economic production assuming failure at year $\mathrm{t}$ (discounted present value)

$\mathrm{LB}(\mathrm{t})=$ the loss of future benefits assuming failure at year $\mathrm{t}$ (discounted present value).

The risk adjusted benefit-cost ratio is recomputed along with the new riskbenefit ratios to determine the effects of warning systems and monitoring of dams.

\section{Silveira, Florentino, Das Neves, Gomes, and Gomes (1984)}

Silveira, Florentino, Das Neves, Gomes, and Gomes (1984) presented criteria for the definition of the monitoring installation and surveillance scheme of dams as a function of risk factors. The overall risk index of potential hazard, $\alpha_{g}$ is estimated from

$$
\alpha_{\mathrm{g}}=E^{*} F^{*} R
$$

where

$$
\begin{aligned}
E= & \text { arithmetic average of indexes relating to external or environmental } \\
& \text { conditions } \\
F= & \text { arithmetic average of indexes relating to dam conditions and reliability } \\
R= & \begin{array}{l}
\text { arithmetic average of the indexes relating to human and economic } \\
\text { potential hazards }
\end{array}
\end{aligned}
$$

\section{U.S. Department of the Interior (1986)}

The U.S. Department of the Interior (1986) presented a warning/evacuation flowchart as well as graphs dealing with Loss of Life vs. Population at Risk for Warning Times. The report dealt with statistical data for baseline projections of Loss of Life and Warning Population at Risk.

\section{Pate-Cornell (1987)}

Pate-Cornell (1987) presented a method to perform probabilistic evaluation and optimization of warning systems and to compare their performance and costeffectiveness with those of other means of risk-management. A decision tree for the monitoring of dams is presented. The basis of the work is the Bayesian analysis of the effects of monitoring dams including various random events. The random events and variables included in the analysis were: potential failure occurrence (annual probability), failure modes, signals occurrence, lead time, potential avoidance of dam failure, and proportion of people saved. 


\section{Bureau of Reclamation Safety of Dams Program (1989)}

The Bureau of Reclamation Safety of Dams Program (1989) discussed procedures for estimating warning time. The data required were inundation maps and travel times for all flood scenarios, descriptions of the loading conditions and failure modes, descriptions of all facilities for direction of the event, and the dam emergency preparedness plan (EPP).

\section{Haimes, Li, Tulsiani, Lambert, and Krzystzofuwicz (1996)}

Haimes, Li, Tulsiani, Lambert, and Krzystzofuwicz (1996) discussed the application of the concepts of risk preference and risk communication to water resources issues. The report dealt with multiobjective decision tree analysis and performance analysis of a flood warning system.

\section{U.S. Department of the Interior Technical Service Center (1999c)}

The U.S. Department of the Interior Technical Service Center (1999c) report discussed the concepts of Early Warning System (EWS), Emergency Action Plan (EAP), detection decision-making, operation, replacement and testing of EWS equipment, and downstream warning and evacuation. The report also discussed EWS design, installation, and operation. 


\section{Recommended Methods For Risk Assessment For Dam Gates}

The literature review was conducted with the intent of identifying potential methods for risk assessment of dams and associated operating equipment. In this chapter, the five identified potential methods for this purpose are discussed in terms of their procedure, advantages, limitations, and application to dam gates (with associated operating equipment). None of the methods in the literature deal with a complete example of a dam gate with associated operating equipment in terms of how to calculate probability of failures for all the critical/top events. There is also no information in the literature as to the calculation of system probability of failure/reliability/risk for dam gates. It is this aspect that will be addressed in Phase II of this research using the identified method of risk assessment and modifying it as needed to meet the goals and objectives of the proposed research.

There exist in the literature several definitions of "Risk" (Cheng, Yen, and Teng 1982). In this report, risk is defined as the probability of failure of the event under consideration. With this premise, the following five methods are recommended based on extensive literature review conducted as part of this research project. These methods (designated A through E for convenience) have a good potential to be used as methods for risk assessment of dams.

\section{A. A Probability Based Evaluation of the Safety and Risk of Existing Dams (Kreuzer and Bury 1984)}

\section{A.1 Procedure}

The procedure assumes availability of information from a recent dam safety inspection. It consists mainly of the following seven steps:

a. Choose a safety criterion. The main equation used is 


$$
P_{f}=P(L \geq R)=\int_{R=0}^{L} \int_{L=0}^{\infty} f_{G}(L) f_{N}(R) d R d L
$$

b. Resolve treatment of data uncertainty. Source data are classified as characteristic values originating primarily from historic records. These source data are then transformed into a suitable form for the safety evaluation. The resulting probability density function or modified data values are termed as design values which enter the safety evaluation.

c. Choose probability density functions. The resistance $R$ is assumed as normal. The load $L$ is assumed to have Gumbel pdf (probability density function), which is given as

$$
f_{G}\left(L, \mu_{L} \sigma_{L}\right)=\frac{1}{\sigma_{L}} \exp [-Z-\exp (-Z)]
$$

where $Z=\left(\frac{L-\mu_{L}}{\sigma_{L}}\right)$

and $\mu_{L} . \sigma_{L}$ are location and scale parameters, respectively. The mean value $(\bar{R})$ and standard deviation $\left(S_{R}\right)$ of resistance $R$ can be expressed as

$$
\begin{aligned}
& \bar{R}=g(\bar{G}, \bar{F}, \bar{M}) \\
& S_{R}=\left[\left(\frac{\delta_{g}}{\delta_{G}} S_{G}\right)^{2}+\left(\frac{\delta_{g}}{\delta_{F}} S_{F}\right)^{2}+\left(\frac{\delta_{g}}{\delta_{M}} S_{M}\right)^{2}\right]^{1 / 2}
\end{aligned}
$$

$\bar{G}$ represents geometry, $\bar{F}$ represents retaining forces, and $\bar{M}$ represents material properties of dam under consideration.

d. Determine resistance mechanisms. The function $g$ of resistance $R$ may express one of several types of resistance mechanisms depending on the type of dam (soil/concrete and/or embankment/gravity) and on the load scenario. These are

(1) Resistance by material strength, leading to cracking.

(2) Shear resistance, leading to instability

(3) Erosion resistance.

e. Select load scenarios. The load scenarios considered are aging, persistent overtopping, transient overtopping, earthquake, and foundation instability with the associated probability of failures being $P_{1}, P_{2} \ldots P_{5}$, respectively. 
A Gumbel distribution of annual flood peaks is assumed. The total failure probability is given as

$$
P_{F}=\sum_{i=1}^{5} P_{i}
$$

f. Analyze failure-consequence. The consequence of a particular failure mode depends on the occurrence of certain associated events such as the rapidity of failure development, early recognition of the hazard, operation of alarm system, etc. Even if the dam does not fail completely, some damage to its structure are possible.

In this reference, authors provide a failure-consequence diagram for an aging scenario (Figure 1). Similar scenarios can be developed for the dam gate problem. Using the failure-consequence diagrams the probabilities $P_{i j}$ of the various failure consequences (such as shown in Figure 1 for aging) can be estimated. Care needs to be exercised in estimating the occurrence probabilities of events associated with a particular type of dam failure.

g. Calculate risk assessment. Finally, the total risk value $\mathrm{R}$ is calculated from

$$
R=\sum_{i=1}^{5} \sum_{j=1}^{4} p_{i j} C_{i j}
$$

where $C_{i j}$ is the monetary value of consequence $\mathrm{j}$ for load scenario $\mathrm{i}$.

\section{A.2 Advantages of the method}

a. The method is generalized enough for application to risk assessment of dams.

b. Resistance mechanisms considered such as resistance by material strength leading to cracking, shear resistance leading to instability, and erosion resistance leading to progressive erosion are practical in nature.

\section{A.3 Limitations of the method}

a. It is assumed that all the load scenarios discussed such as aging, persistent overtopping, transient overtopping, earthquake, and foundation instability are mutually exclusive events which may not be true in all cases. That limits the applicability of the method.

b. Assumes that information from a recent dam safety inspection is available. 


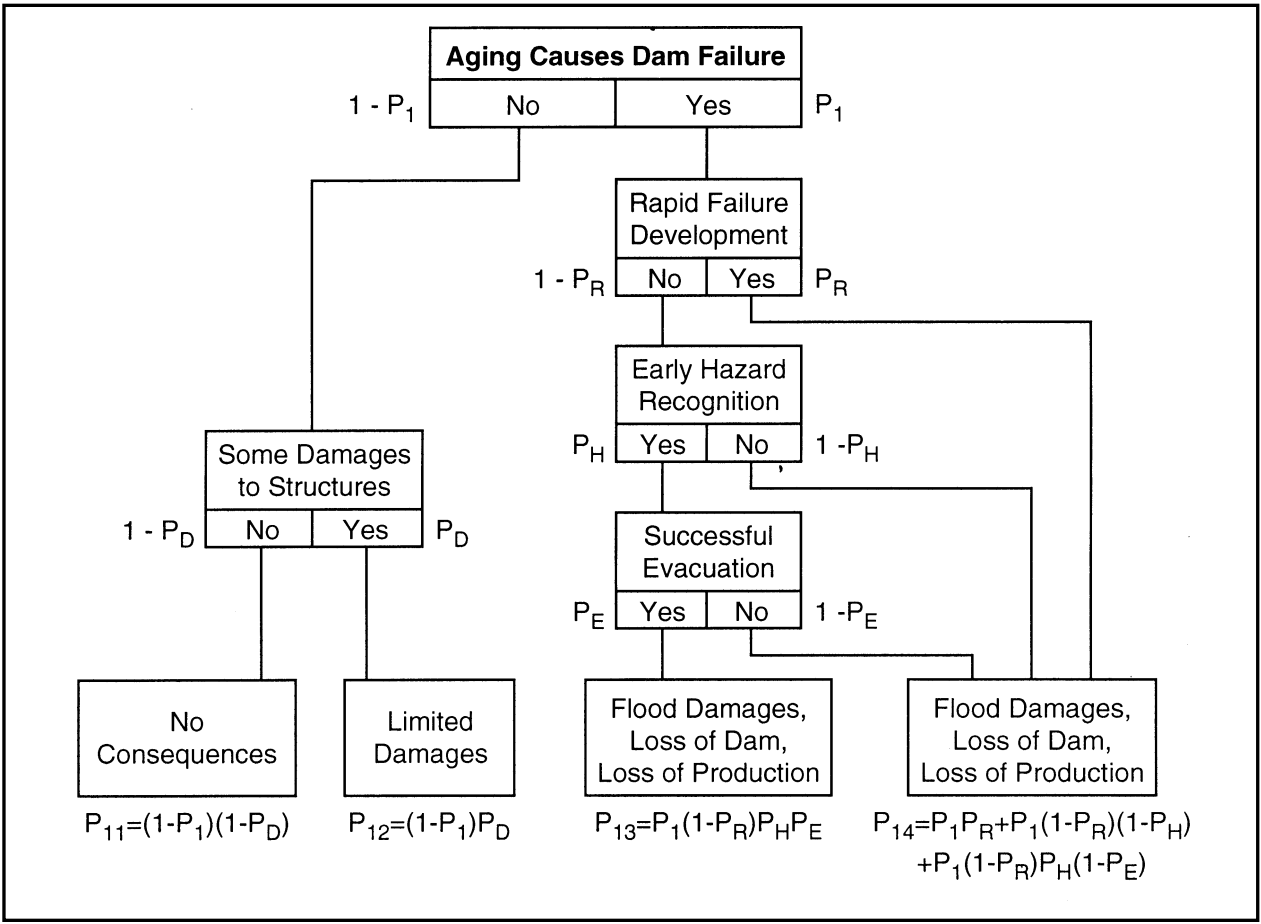

Figure 1. Failure-consequence diagram for an aging scenario (Kreuzer and Bury 1984)

c. No discussion of associated operating equipment is included.

d. No practical and complete example dealing with calculation of dam gate failure probabilities is discussed.

\section{A.4 Application to dam gates and associated operating equipment}

a. Identify all primary failure causes and hazardous conditions for dam gates and/or associated operating equipment.

$b$. Determine failure probabilities using basic probability principles using proper resistance and load functions.

c. Calculate the total failure probability assuming that all the events are mutually exclusive.

d. Finally calculate the total risk value.

\section{B. Wind Induced Overtopping Risk of Dams (Cheng et al. 1986a)}

\section{B.1 Procedure}

The method involves the following steps: 
a. Formulate a failure criterion leading to the corresponding performance function.

$b$. Determine probability of dam failure due to any cause (in this case wind overtopping), $\mathbf{b}_{f}$ is evaluated using the Advanced First-Order SecondMoment Method of risk analysis or Monte Carlo simulation.

c. Determine the corresponding overtopping risk from $\mathrm{P}_{f}$ and the random nature of occurrence of wind in a given time period. The necessary expressions are given below:

$$
\mathbf{P}_{f}=P(Z<0)
$$

where

$$
\begin{aligned}
Z & =\left(H_{C}-H_{O}\right) \\
& -\left[\frac{V_{W}^{2} F}{1400 D}+0.034 a V_{W}^{1.06} F_{e}^{0.47} \exp \left(-0.028 b V_{W}^{0.18} / F_{e}^{0.09}\right)\right](6 \mathrm{bis})
\end{aligned}
$$

where

$$
\begin{aligned}
& H_{C}=\text { elevation of the crest of the dam } \\
& H_{O}=\text { undisturbed reservoir water level } \\
& V_{W}=\text { wind velocity in miles/hour } \\
& F=\text { fetch or length of water surface in miles over which wind blows } \\
& D=\text { average depth of reservoir } \\
& F_{e}=\text { effective fetch } \\
& a, b=\text { coefficients of embankment slopes }
\end{aligned}
$$

Finally the risk of overtopping due to wind can be calculated from

$$
P_{W}(T)=1-\exp \left(-\mathrm{v}_{w} T \mathrm{p}_{f}\right)
$$

where $v_{w}$ is mean occurrence rate of wind and $T$ is the period of time under consideration.

As is evident, the performance function $Z$ will change depending on the failure criterion. The AFOSM method is used for evaluation of Equation 24. Details of the AFOSM Method are available in literature (Ang and Tang 1984; Ellingwood et al. 1980; Yen, Cheng, and Melching 1986). If obtaining derivatives is an involved process (due to nonlinearity of function) leading to inaccuracies, then the AFOSM method 
will give erroneous results. Hence, alternatively Monte Carlo simulation can be used. (Ang and Tang 1984, Melchers 1979).

\section{B.2 Advantages of the method}

a. The well known Advanced First Order Second-Moment Method (AFOSM) is used for probability of failure calculation.

$b$. The derivation of the performance function for overtopping of dam is clearly illustrated, along with the risk of overtopping due to wind.

c. A practical example of an earth dam is considered to discuss the efficacy of the method.

\section{B.3 Limitations of the method}

a. The AFOSM method could be very involved and time-consuming for complex dam structures.

b. No other performance function (other than overtopping of dam) is considered.

c. No examples of associated operating equipment are discussed.

\section{B.4 Application to dam gates and associated operating equipment}

a. Choose performance functions for various limit states dealing with dam gates and associated operating equipment.

$b$. For each performance function, calculate the probability of failure (using AFOSM) and hence the risk value using the expression given in this paper.

c. Develop expressions for system risk as part of the future research if this method is implemented.

\section{Probabilistic Risk Analysis of Large Dams: Its Value and Limits (Lafitte 1993) Based on Method by Gruetter and Schnitter (1982)}

\section{C.1 Procedure}

In this paper, risk is treated as a measure of the extent of danger, established by relating an evaluation of the probability of an undesirable event occurring to an evaluation of its effects or consequences. 
The basic equation used is

$$
R=P D^{\alpha}
$$

where

$P=$ probability of the occurrence of the undesirable event

$D=$ probable extent of the damage caused risk

$\alpha=$ risk consequence factor

The method consists of the following steps:

a. Identify the events which could cause a failure. Fault trees for the dam relating to causes should be formulated at this stage (similar to Podgorski, Putcha, and Ryan 2000). Figure 2 shows the fault tree for persistent overtopping of dam.

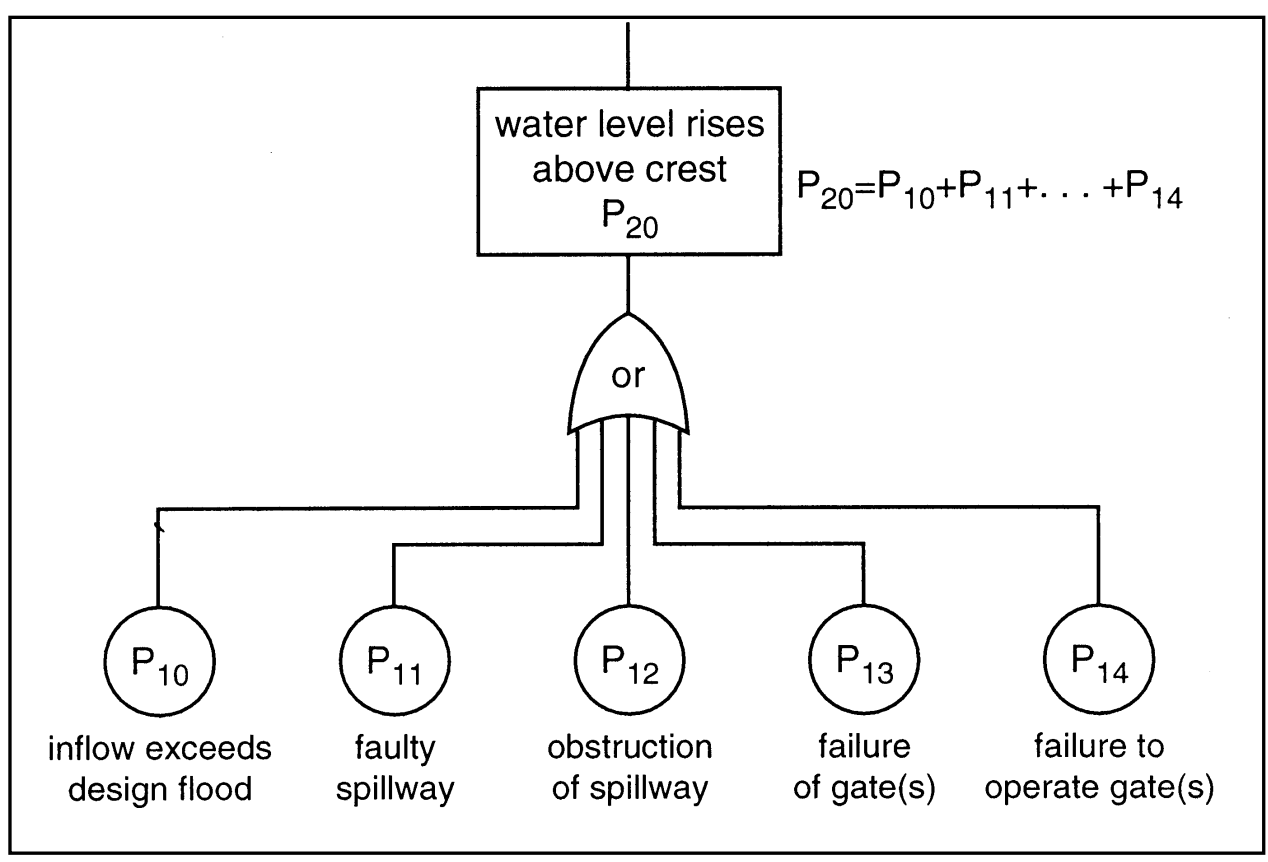

Figure 2. Fault tree for persistent overtopping of a dam (Lafitte 1993)

$b$. Determine the probability of occurrence of loads on the dam as a result of the events defined in Step $a$ above. This will give $P$ in Equation 12.

c. Determine the probability of dam failure as a result of each load. The failure mechanisms should be defined for each case. Monte Carlo simulation could be used for this. 
d. Estimate the consequences of each mode of failure. This requires a study of the zones flooded by the wave created by dam breach, and the consequent losses.

Event trees relating to consequences should be formulated at this stage (Figure 3). Steps $c$ and $d$ will give $\mathrm{D}$ in Equation 12.

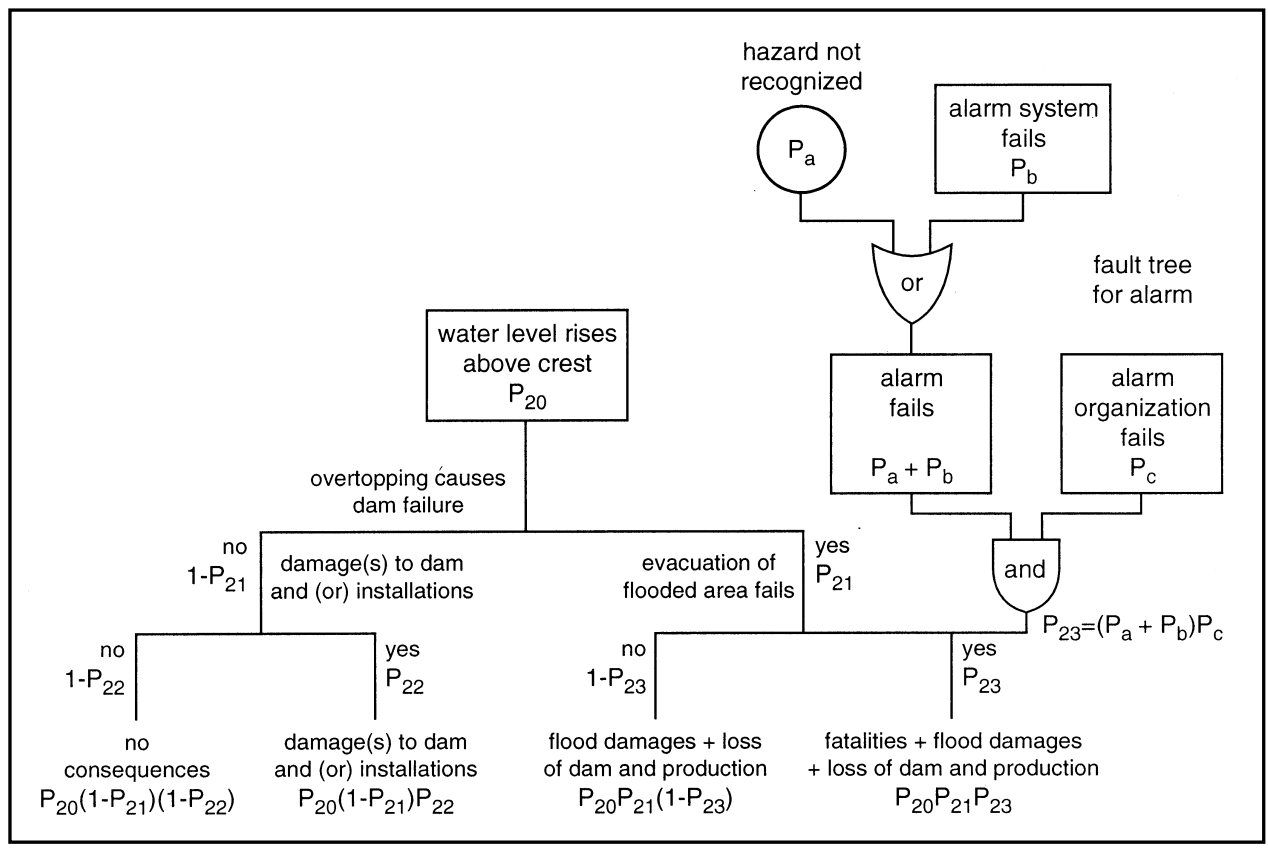

Figure 3. Event tree for persistent overtopping of a dam (Lafitte 1993)

e. Assign $\alpha$ a value between 0 and 1 based on expert judgment to appropriately adjust the severity of risk of the event.

f. Calculate risk $R$ from Equation 12 .

\section{C.2 Advantages of the method}

a. The risk $(R)$ is expressed through a simple equation using three parameters, $P$ (Probability of Occurrence of Undesirable Event), $D$ (Probable Extent of Damage), and $\alpha$ (Risk Factor Based on Consequences).

b. Fault-tree analysis and event-tree analysis are used for causes and consequences.

\section{C.3 Limitations of the method}

a. No discussion of associated operating equipment is done in the paper but may be added similarly. 
$b$. No range of the $\mathrm{P}, \mathrm{D}$, and $\alpha$ values is given for the user.

c. No practical and complete example dealing with calculation of dam gate failure probabilities is discussed in the paper.

\section{C.4 Application to dam gates and associated operating equipment}

a. Develop fault trees for each top event for dam gates as well as for the associated operating equipment (similar to the one for persistent overtopping of dam developed in the paper and other references (Henley and Kumamoto 1981; Ebeling 1997; Ayyub 1997)).

$b$. Calculate the probability of failure of each basic event $(P)$ using Monte Carlo simulation.

c. Calculate the probability extent of damage $(D)$ using again Monte Carlo simulation.

d. Use the risk expression (Equation 12) to calculate the risk of any top event.

e. Calculate the system risk. Some kind of upper/lower bounds have to be developed as part of the research if this method is picked for implementation in future research.

\section{Predicting Loss of Life in Cases of Dam Failure and Flash Flood (Dekay and McClelland 1993)}

\section{D.1 Procedure}

In this method, Loss of Life (LOL), that may result from dam failures and flash floods, is treated as a key parameter. An expression is derived for $L O L$ :

$$
L O L=\frac{P A R}{1+13.277\left(P A R^{0.440}\right) \exp (0.759(W T)-3.790(F O R C E)+2.223(\text { WT })(F O R C E))}(11
$$

where

$$
\begin{gathered}
P A R=\text { population at risk } \\
W T=\text { warning time } \\
F O R C E=\text { forcefulness of flood waters }
\end{gathered}
$$

Separate equations are derived for High Force $(\mathrm{HF}$ - Force $=1)$ or for Low Force $(\mathrm{LF}$ - Force $=0)$. These are given below: 


$$
\begin{aligned}
L O L_{H F} & =\frac{P A R_{H F}}{1+13.277\left(P A R_{H F}^{0.440}\right) \mathrm{e}^{\left[2.982\left(W T_{H F}\right)-3.790\right]}} \\
L O L_{L F} & =\frac{P A R_{L F}}{1+13.277\left(P A R_{L F}^{0.440}\right) \mathrm{e}^{\left[0.759\left(W T_{L F}\right)\right]}}
\end{aligned}
$$

Probability of $L O L$ exceeding a given threshold level of $L O L$ can then be determined indicating the risk of dam failure.

\section{D.2 Advantages of the method}

a. Loss of life in cases of dam failure is discussed in detail.

b. Closed form expressions for loss of life in terms of $P A R$ (Population At Risk), WT (Warning Time), and FORCE (Forcefulness of Flood Waters) are provided which can easily be applied to a dam problem.

\section{D.3 Limitations of the method}

a. No methodology is provided for the actual failure probability calculation of a dam gate.

b. No discussion is provided for probability of loss of life $(L O L)$ in case of dam failure.

c. Associated operating equipment as it relates to a dam gate is not discussed at all.

\section{D.4 Application to dam gates and associated operating equipment}

This method can only be used for associated operating equipment only if it causes Loss of Life as the method predominately deals with Loss of Life.

a. Calculate loss of life in case of dam failure using the PAR (Population At Risk) and FORCE (Forcefulness of Flood Water) using Equation (11).

b. Calculate probability of $L O L$ for dam failure using Monte Carlo simulation.

\section{E. Classes Of Risk For Dams (Lafitte 1996)}

\section{E.1 Procedure}

The method proposed is based on a method outlined in ICOLD bulletin on automation in the monitoring of dam safety [ICOLD 1982]. The method is as follows: 
a. Identify the principal criteria associated with monitoring the dam safety. These are:

(1) General Conditions of the Site (CGS)

(2) Condition of the Structure (CO)

(3) Socio-Economic Conditions downstream of the dam (CSE)

$b$. Identify the partial criteria for each of the principal criteria listed in $a$.

(1) CGS
A - Seismicity
B - Hydrology
C - Transport of Floating Debris
D - Climatic Conditions
E - Geology of the Site
F - Potential Sliding in the Reservoir

(2) $\mathrm{CO}$

G - Design of the Structure

$\mathrm{H}$ - Design of the Foundations

I - Fluctuations in the Reservoir Level

J - Spillway

K - Low Level Outlets

L - Instrumentation, Operation, and Maintenance

(3) CSE

M - Hazard for the Population

$\mathrm{N}$ - Hazard for Inhabited Areas, Agriculture, Commerce, and Industry

O - Hazard for the Infrastructure

P - Warning of the System

c. Based on expert assessment, assign appropriate weighting factors for each of the three principal criteria related to dam safety, as well as partial criteria associated with each of the principal criteria. (See Table 1.) 


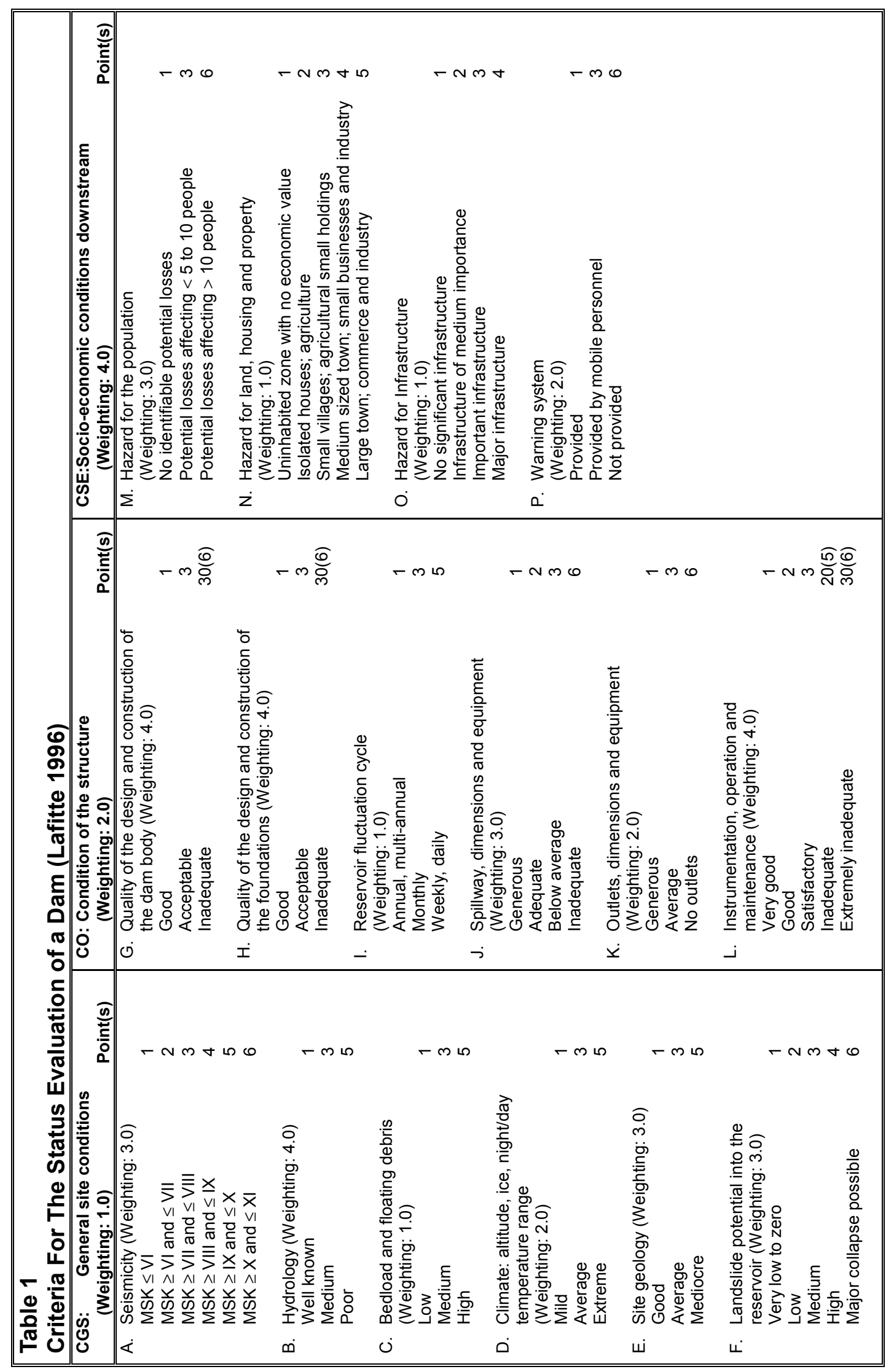


d. Calculate the partial factors for each of the three principal criteria.

e. Finally, calculate the global factor for the dam.

\section{E.2 Advantages of the method}

a. A simple procedure for evaluation of risk based on the characteristics of dam and reservoir (like design and general condition and the way in which it is maintained) is provided.

b. The risk of dam is calculated using simple relation for Global Factor (FG) using partial factors from Table 1.

\section{E.3 Limitations of the method}

a. The method deals more with monitoring of dam safety.

$b$. The whole method is based on subjective partial and global factors.

c. No method is provided for calculation of probability of failure for any limit state, so as to form an input for risk calculation.

\section{E.4 Application to the dam gates and associated operating equipment}

a. For dam gate or associated operating equipment, estimate the Condition of the Site (CGS), Condition of the Structure (CO), and Socio-Economic Conditions Downstream (CSE) as applicable.

b. Calculate partial factors for each case and then calculate Global Factor (FG).

c. From FG obtain an idea of the overall ranking of dam. 


\section{Conclusions}

Based on the extensive literature review performed as part of this research project five methods are identified as potential methods for risk assessment of dam gates.

The method of Kreuzer and Bury (1984) was picked as one of the potential methods of risk assessment because their paper provided a systematic presentation for probability of failure for a dam with available information from a dam safety inspection. The method of Cheng, Yen, and Tang (1986) was picked as a potential method for risk assessment because of its use of a well known reliability method (AFOSM for reliability calculation) for any given performance function. The method of Lafitte (1993) was picked as a potential method for risk assessment because of its usage of fault-tree analysis and event-tree analysis for probability of failure calculation. This method has an extra advantage because of a simple relation for risk calculation using probability of failure values. The method of Dekay and McCelland (1993) was picked as a potential method for risk assessment because of its easy usage of calculation of Loss of Life (LOL) in case of dam failure. Another method of Lafitte (1996) was picked as a potential method for risk assessment for classifying the dams based on the global factors.

After a thorough review of all the recommended methods, the method of Lafitte (1993) is recommended for risk assessment of dams and associated operating equipment. This should be used as a start for Phase II of this project.

Regarding warning systems for dams, only a brief literature review was performed in this project; hence, no recommendation is made in this regard.

The method of Lafitte (1993) should be used as a part of Phase II research work for risk assessment of dam gates and associated operating equipment. 


\section{References}

Alla, A. A. (1996). "The role of fusegates in dam safety," International Journal on Hydropower and Dams 3(6).

Ang, A. H-S, and Tang, W. H. (1984). Probability concepts in engineering, planning and design. Vol. II, John Wiley \& Sons.

Apostolakis, G. (1989). "Expert opinions in probabilistic safety assessment." Risk-Based Decision Making in Water Resources, Proceedings of ASCE $4^{\text {th }}$ Conference Sponsored by Engineering Foundation. Oct. 15-20. ASCE, New York.

Ayyub, B. M. (1997). Probability, statistics and reliability for engineers. CRC Press, Boca Raton, FL.

Barlow, R. E., and Proschan, F. (1965). Statistical theory of reliability. John Wiley \& Sons.

. (1981). Statistical theory of reliability and life testing: Probability models. To Begin With, Silver Springs, MD.

Bivins, W. S. (1981). "Risk analysis applications in dam safety." Proceedings of the International ANS/ENS Topical Meeting on Probabilistic Risk Assessment. American Nuclear Society.

. (1983). "Dam safety - An overview of a risky business,"

Proceedings, Conference on Frontiers in Hydraulic Engineering. ASCE, New York.

Boccotti, P., and Rosso, R. (1984). "Risk analysis of spillway design floods." Proceedings of the International Conference on Safety of Dams. Coimbra, April 23-28. Edited by J. Laginha Serafim, University of Coimbra, Portugal.

Bohnenblust, H., and Vanmarcke, E. H. (1982). "Decision analysis for prioritizing dams for remedial measures: A case study," Report of the Project "Risk-Based Assessment of the Safety of Dams" No. 732. Massachusetts Institute of Technology, Cambridge, MA. 
Bowles, D. (1990). "Risk assessment in dam safety decision making." RiskBased Decision Making in Water Resources, Proceedings of $4^{\text {th }}$ Conference. Y. Y. Haimes and E. Z. Stakhiv, ed. ASCE, New York.

Bury, K., and Kreuzer, H. (1985). "The assessment of the failure probability for a gravity dam," Water Power and Dam Construction; November.

(1986). "The assessment of risk for a gravity dam," Water Power and Dam Construction; December.

Bureau of Reclamation Safety of Dams Program. (1989). "Policy and procedures for dam safety modification decision making,. Department of the Interior Bureau of Reclamation. Denver, CO.

Cheng, S-T, Yen, B. C., and Tang, W. H. (1982). "Overtopping risk for an existing dam, civil engineering studies," Hydraulic Engineering Series No. 37, Department of Civil Engineering, University of Illinois, Urbana.

. (1986a). "Wind-induced overtopping risk of dams." B. C. Yen, ed., Stochastic and Risk Analysis in Hydraulic Engineering. Water Resources Publications, Littleton, CO.

. (1986b). "Sensitivity of risk evaluation to coefficient of variation." B. C. Yen, ed., Stochastic and Risk Analysis in Hydraulic Engineering. Water Resources Publications, Littleton, CO.

Committee on the Safety of Existing Dams, Water Science and Technology Board, Commission on Engineering and Technical Systems and National Research Council. (1983). Safety of existing dams evaluation and improvement. National Academy Press, Washington, DC.

Croucamp, W. S., and Carmichael, G. P. (1984). "Remarkable floods of 1981 in South Africa which overtopped several dams." Proceedings of the International Conference on Safety of Dams. Coimbra, April 23-28. Edited by J. Laginha Serafim, University of Coimbra, Portugal.

Dekay, M. L., and McClelland, G. (1993). "Predicting loss of life in cases of dam failure and flash flood," Risk Analysis 13(2).

Department of the Army. (1982). "National program of inspection of non-federal dams," Final Report to Congress, Office of the Chief of Engineers. Washington, DC. . (1997). "Reliability analysis of navigational lock and dam mechanical and electrical equipment," Engineer Technical Letter, 1110-2549, U.S. Army Corps of Engineers, Washington, DC.

Derman, C., and Ross, S. (1995). "Reliability for a system with dependent components." Probability in the engineering and informational sciences 9, Cambridge University Press, London, Cambridge, USA. 
Dhillon, B. S., and Singh, C. (1981). Engineering reliability. John Wiley \& Sons, New York.

Draper, W. R., Evans, M., and Guttman, I. (1989). "A Bayesian approach to system reliability when two components are dependent," Computational Statistics and Data Analysis 7. Elsevier Science Publishers, North Holland.

Duscha, L. (1984). "Dam safety in the United States: What has been gained?" Proceedings of the International Conference on Safety of Dams. Coimbra, April 23-28. Edited by J. Laginha Serafim, University of Coimbra, Portugal.

Ebeling, C. E. (1997). An introduction to reliability and maintainability engineering. McGraw Hill, Inc., New York.

Ellingwood, B., Galambos, T. V., MacGregor, J. G., and Cornell, C. A. (1980). "Development of a probability based load criterion for American Standard A58: Building code requirements for minimum design loads in buildings and other structures," NBS Special Publication 577.

Fannelli, M., Giuseppetti, C., Bonaldi, P., Marazo, A., and Riccioni, R. (1984). "Simulation of service life of a dam: A new approach to design and safety evaluation." Proceedings of the International Conference on Safety of Dams. Coimbra, April 23-28. Edited by J. Laginha Serafim, University of Coimbra, Portugal.

Gruetter, F., and Schnitter, N. J. (1982). "Analytical risk assessments for dams," Transactions $-14^{\text {th }}$ International Congress on Large Dams, Rio de Janeiro, Brazil.

Hagen, V. K. (1982). "Re-evaluation of design floods and dam safety." Transactions of $14^{\text {th }}$ International Congress On Large Dams 1, Rio de Janeiro, Brazil.

Haimes, Y. Y., Li, D., Tulsiani, V., Lambert, J. H., and Krzysztofuwicz, R. (1996). "Risk-based evaluation of flood warning and preparedness systems report, Vol 2," U.S. Army Corps of Engineers, Washington, DC.

Haimes, Y. Y, Petrakian, R., Karlsson, P-O, and Mitsiopoulos, J. (1988). "Multiobjective risk partitioning: An application to dam safety risk analysis," Institute for Water Resources Report No. 88-R-4, U.S. Army Corps of Engineers, Washington, DC.

Henley, E. J., and Kumamoto, H. (1981). Reliability engineering and risk assessment. Prentice-Hall, Inc., Englewood Cliffs, NJ.

ICOLD Bulletin. (1982). "Automation in monitoring the safety of dams," Bulletin No. 4, International Commission on Large Dams, Paris, France. 
Iyer, S. (1992). "The Barlow-Proschan importance and its generalizations with dependent components." Stochastic processes and their applications. NorthHolland.

Karlsson, P-O, and Haimes, Y. Y. (1989). "Risk assessment of extreme events: Application," Journal of Water Resources Planning Management 115(3).

Kreuzer, H., and Bury, K. (1984). "A probability based evaluation of the safety and risk of existing dams." Proceedings of the International Conference on Safety of Dams. Coimbra, April 23-28. Edited by J. Laginha Serafim, University of Coimbra, Portugal.

Lafitte, R. (1993). "Probabilistic risk analysis of large dams: Its value and limits," International Water Power \& Dam Construction 45(3).

. (1996). "Classes of risk for dams," International Journal on Hydropower and Dams 3(6).

Langseth, A. M., and Perkins, M. (1983). "The influence of dam failure probabilities on spillway analysis." Proceedings of Conference on Frontiers in Hydraulic Engineering. ASCE, New York.

Lee, H-L., and Mays, L. W. (1983). Advances in risk and reliability analysis for hydraulic structures." Proceedings of Conference on Frontiers in Hydraulic Engineering. ASCE, New York.

Leemis, L. M. (1995). Reliability: Probabilistic models and statistical methods. Prentice Hall, Inc., Englewood Cliffs, NJ.

Li, K. V., and Li, V.D.K. (1989). "Modeling and analysis of systems with multimode components and dependent failures," IEEE Transactions on Reliability $38(1)$.

Lytle, J. D. (1984). "Dam safety monitoring: Instrumentation, observation and evaluation. Proceedings of the International Conference on Safety of Dams. Coimbra, April 23-28. Edited by J. Laginha Serafim, University of Coimbra, Portugal.

Mays, L. (1987). "Review of advances in risk and reliability analysis for hydraulic structures." Application of frequency and risk in water resources. V. P. Singh, ed. Reidel Publishing Company.

McCann, M., Franzini, J. B., Kavazanjian, E., and Shah, H. C. (1985). "Preliminary safety evaluation of existing dams," Volumes I and II, Report prepared for Federal Emergency Management Agency. Department of Civil Engineering, Stanford University, Stanford, CA.

Melchers, R. E. (1979). Structural reliability analysis and prediction. Ellis Horwood, Chichester, W. Sussex, England. 
Melching, C. S. Wenzel, H., and Yen, B. C. (1987). "Application of system reliability analysis to flood forecasting," Application of Frequency and Risk in Water Resources. V. P. Singh, ed. Reidel Publishing Company.

Military Standard (MIL-STD-1629A). (1980). "Procedures for performing a failure mode, effects and criticality analysis." Naval Publications and Forms Center, Philadelphia, PA.

Nelson, Wayne (1982). Applied data life analysis. John Wiley \& Sons, New York.

Parrett, N. F. (1987). "Bureau of Reclamation use of risk analysis," Application of Frequency and Risk in Water Resources. V. P. Singh, ed. Reidel Publishing Company.

Pate-Cornell, M. E. (1984). "Warning systems: Application to the reduction of risk costs for new dams." Proceedings of the International Conference on Safety of Dams. Coimbra, April 23-26. Edited by J. Laginha Serafim, University of Coimbra, Portugal. . (1987). "Warning systems in risk management: The benefits of monitoring." Risk analysis and management of natural and man-made hazards. Proceedings ASCE, November. ASCE, New York.

Petrakian, R., Haimes, Y. Y., Stakhiv, E. and Moser, D. A. (1989). "Risk analysis of dam failure and extreme floods." Risk analysis and management of natural and man-made hazards. Y. Y. Haimes and E. Z. Stakhiv, ed. ASCE, New York.

Podgorski, R., Putcha, C., and Ryan, K. (2000). "Failure modes and effects analysis (FMEA) for the orbiter forward reaction control system (FRCS) interconnect (IC) system (FICS)." Safety and reliability engineering, Boeing North America, Inc., Seattle, WA.

Priscu, R., and Stematiu, D. (1984). "Some design criteria for large dams on basis of probabilistic concept of safety." Proceedings of the International Conference on Safety of Dams. Coimbra, April 23-28. Edited by J. Laginha Serafim, University of Coimbra, Portugal.

Putcha, C. S., and Patev, R. C. (1997). "Methodologies for use in timedependent reliability analyses." Uncertainty modelling and analyses in civil engineering. B. Ayyub, ed. CRC Press, Inc.

Resendiz-Carrillo, D., and Lave, L. B. (1987). "Optimizing spillway capacity with an estimated distribution of floods," Water Resources Research 23(11).

Schöttl, A. (1996). "A reliability model of a system with dependent components," IEEE Transactions on Reliability 45(2), June. 
Serafim, J. L. (1984). "Reliability assessment of concrete dams from the probability of exceptional loads and defective properties of materials and foundations." Proceedings of the International Conference on Safety of Dams. Coimbra, April 23-28. Edited by J. Laginha Serafim, University of Coimbra, Portugal.

Shooman, M. L. (1990). Probabilistic reliability: An engineering approach. Robert E. Kreiger Publications, Malabar, FL.

Silveira, A. F. (1984). "Statistical analysis of deteriorations and failures of dams." Proceedings of the International Conference on Safety of Dams. Coimbra, April 23-28. Edited by J. Laginha Serafim, University of Coimbra, Portugal.

Silveira, A. F., Florentino, C. A., Das Neves, E. M., Gomes, A. S., and Gomes, J. C. (1984). "Monitoring dams according to risk factors." Proceedings of the International Conference on Safety of Dams. Coimbra, April 23-26. Edited by J. Laginha Serafim, University of Coimbra, Portugal.

Stedinger, J., Heath, D., and Nagarwalla, N. (1989). "Event tree simulation analysis for dam safety problems risk analysis." Risk Analysis and Management of Natural and Man-Made Hazards. Y. Y. Haimes and E. Z. Stakhiv, ed. ASCE, New York.

Systems Safety and Reliability. (1992). "Guidelines for performing failure modes and effects analysis (FMEA) and critical items list (CIL) on software logic designs," National Aeronautics and Space Administration (NASA).

Thompson, K. D., Stedinger, J. R., and Heath, D. C. (1997). "Evaluation and presentation of dam failure and flood risks," Journal of Water Resources Planning and Management 123(4).

U.S. Department of the Interior Bureau of Reclamation. (1983). Safety evaluation of existing dams, " a Water Resources Technical Publication, Denver, Colorado. . (1986). Guidelines to decision analysis. Denver, CO.

U.S. Department of the Interior Technical Service Center. (1999a). "Critical areas and documented failures of mechanical equipment at the spillway and outlet works areas of Bureau of Reclamation Facilities," Report for U.S. Army Corps of Engineers Work Unit No. 33262, Probability of Failure of Gates, Equipment and Warning Systems.

. (1999b). "Inventory of mechanical equipment at the spillway and outlet works areas of Bureau of Reclamation Facilities," Report for U.S. Army Corps of Engineers Work Unit No. 33262, Probability of Failure of Gates, Equipment and Warning Systems. 
U.S. Department of the Interior Technical Service Center. (1999c). "Early warning systems at Bureau of Reclamation facilities," Report for U.S. Army Corps of Engineers Work Unit No. 33262, Probability Of Failure of Gates, Equipment and Warning Systems.

Vanmarcke, E. H. (1984). "Risk management to improve dam safety." Proceedings of the International Conference on Safety of Dams. Coimbra, April 23-28. Edited by J. Laginha Serafim, University of Coimbra, Portugal.

Vanmarcke, E. H., and Bohnenblust, H. (1982). "Risk-based decision analysis in dam safety," Report of the Project Risk-Based Assessment of Safety of Dams. No. 731, Massachusetts Institute of Technology, Cambridge, MA.

Vick, S. G., and Bromwell, L. G. (1989). "Risk analysis for dam design in karst," Journal of Geotechnical Engineering, ASCE 115(6).

Von Thun, J. L. (1984). "Application of decision analysis techniques in dam safety evaluation and modification." Proceedings of the International Conference on Safety of Dams. Coimbra, April 23-28. Edited by J. Laginha Serafim, University of Coimbra, Portugal.

Widmann, R. (1984). "Possibilities of improving the safety of large dams." Proceedings of the International Conference on Safety of Dams. Coimbra, April 23-28. Edited by J. Laginha Serafim, University of Coimbra, Portugal.

Yen, B. C., Cheng, S-T, and Melching, C. S. (1986). "First order reliability analysis." Stochastic and risk analysis in hydraulic engineering. B. C. Yen, ed. International Association of Hydraulic Research.

Yen, B. C., Cheng, S-T, and Tang, W. T. (1980). "Reliability of hydraulic design of culverts." Proceedings of International Conference on Water Resources Development. Taipei, China, May 12-14. International Association of Hydraulic Research. 


\section{REPORT DOCUMENTATION PAGE}

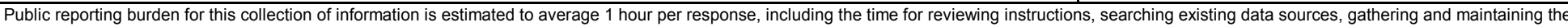

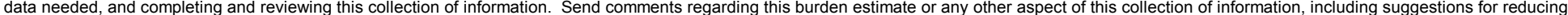

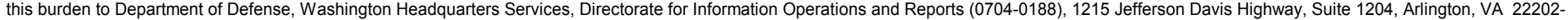

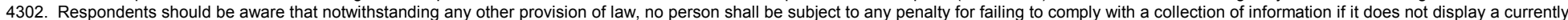
valid OMB control number. PLEASE DO NOT RETURN YOUR FORM TO THE ABOVE ADDRESS

\begin{tabular}{l|l|l|l|l} 
1. REPORT DATE (DD-MM-YYYY) & 2. REPORT TYPE & 3. DATES COVERED (FrOm - To)
\end{tabular}

November $2000 \quad$ Final report

\section{TITLE AND SUBTITLE}

5a. CONTRACT NUMBER

Investigation of Risk Assessment Methodology for Dam Gates and Associated Operating Equipment

5b. GRANT NUMBER

5c. PROGRAM ELEMENT NUMBER

\section{AUTHOR(S)}

Chandra S. Putcha, Robert C. Patev

5d. PROJECT NUMBER

5e. TASK NUMBER

5f. WORK UNIT NUMBER

\section{PERFORMING ORGANIZATION NAME(S) AND ADDRESS(ES)}

California State University, Fullerton, CA 92834;

U.S. Army Engineer Research and Development Center

Information Technology Laboratory

8. PERFORMING ORGANIZATION REPORT NUMBER

3909 Halls Ferry Road

Vicksburg, MS 39180-6199

9. SPONSORING / MONITORING AGENCY NAME(S) AND ADDRESS(ES)

10. SPONSOR/MONITOR'S ACRONYM(S)

U.S. Army Corps of Engineers

Washington, DC 20314-1000

11. SPONSOR/MONITOR'S REPORT NUMBER(S)

\section{DISTRIBUTION / AVAILABILITY STATEMENT}

Approved for public release; distribution is unlimited.

\section{SUPPLEMENTARY NOTES}

\section{ABSTRACT}

This report deals with investigation of risk assessment methodologies, existing in literature, pertaining to dam gates and associated operating equipment conducted in Phase I of this research. More than 60 references have been studied in detail as part of the work. Based on this, five methods have been identified as potential methods for risk assessment of dam gates. These are: Dekay and McClelland (1993), Cheng et al. (1986), Lafitte (1993), Lafitte (1996), Kreuzer and Bury (1984). Dekay and McClelland (1993) proposed a method for predicting Loss of Life (LOL) resulting from dam failures and flash floods. An empirical equation has been derived for LOL in terms of Population At Risk (PAR), Warning Time (WT) and Forcefulness of Flood Waters (FORCE). Cheng et al. (1986) propose calculation of probability of failure due to any cause using Advanced First Order Second Moment (AFOSM) method for the formulated performance function. Lafitte (1993) proposed an equation for calculation of Reliability $(\mathrm{R})$ in terms of probability of occurrence of the undesirable event $(\mathrm{P})$, and the probable extent of the damage caused (D) and a risk consequence factor $(\alpha)$. Lafitte (1996) proposed a method for classifying the risk for dams based on the calculation of the global factor for each dam. The method incorporates the General Conditions of the Site (CGS), condition of the structure (CO), and

\begin{tabular}{|c|c|c|c|c|c|}
\hline & & & & & (Continued) \\
\hline 15. SUBJECT TERMS & Density fi & ction & erdependencies & Reliabil & Safety \\
\hline Assessment & Dependen & & ertopping & Reservo & Systems \\
\hline Dams & Gates & & bability & Risk & \\
\hline 16. SECURITY CLASS & FICATION OF: & & 17. LIMITATION & 18. NUMBER & 19a. NAME OF RESPONSIBLE PERSON \\
\hline $\begin{array}{l}\text { a. REPORT } \\
\text { UNCLASSIFIED }\end{array}$ & $\begin{array}{l}\text { b. ABSTRACT } \\
\text { UNCLASSIFIED }\end{array}$ & $\begin{array}{l}\text { c. THIS PAGE } \\
\text { UNCLASSIFIED }\end{array}$ & & 53 & $\begin{array}{l}\text { 19b. TELEPHONE NUMBER (include area } \\
\text { code) }\end{array}$ \\
\hline
\end{tabular}




\section{ABSTRACT (Concluded)}

socio-economic conditions downstream of dam (CSE). Kreuzer and Bury (1986) discussed a procedure using safety criterion, treatment of data uncertainty and choice of probability density function. The final recommended method is the one proposed by Lafitte (1993). Phase II will focus on implementation of method proposed by Lafitte (1993) to an actual dam gate and associated operating equipment. 
Destroy this report when no longer needed. Do not return it to the originator. 